\title{
Miso-vortices along an oceanic cold front- 27 November 2015
}

\author{
David Smart, UCL Hazard Centre, University College London. \\ d.smart@ucl.ac.uk \\ ACCEPTED at Weather, 2016 \\ PUBLISHED March 2017, v72, no 3
}

\begin{abstract}
During the autumn and winter months strong cold fronts with 'Narrow Cold-Frontal Rainbands' marking their surface positions (NCFRs) are frequently observed in the environs of the British Isles as cold polar maritime air penetrates equatorwards. For two recent examples in the month of November see Young (2014) and Kidd (2015) and references therein.
\end{abstract}

Figure 1 is a processed Meteosat Second Generation geostationary satellite visible image for 1315 UTC 27 November 2015. A band of cloud can be seen trailing from western Scotland south-south-westwards through the Irish Sea and west of the Bay of Biscay. According to the Met Office surface analysis for 12 UTC 27 November (not shown) this marked a double cold front trailing from the Norwegian Sea to the central North Atlantic. A minor wave along this front is marked by the ill-defined arc of cloud over Ireland and stretching to the Western Isles. Cold air flooding southwards is characterised by shallow open-cell convection in the eastern Atlantic.

Equatorward of the frontal wave and embedded within this wide cold-frontal rainband a much narrower string of brighter cloud tops can be seen illuminated by the relatively low angle winter sun. This suggests slightly higher cloud tops characteristic of a NCFR consisting of shallow linear cumulus clouds or 'line convection'. In this case the line convection is distorted by a regular wave-like perturbation reminiscent of a 'daisy chain' or 'string of pearls'. At regular intervals and at the apices of the chain are dark holes, marked by arrows in the figure. Examination of contemporaneous infra-red imagery (not shown) supports the interpretation that these are indeed cloud free holes through which the ocean surface can be seen.

The regular spacing of the holes and their quasi-circular to elliptical appearance suggest they are shallow vortices. Miso-vortices or misocyclones, occasionally accompanied by tornadoes, have been reported on NCFRs over land (eg. Smart and Browning, 2009). Smart and Browning (2009) modelled the structure of these misocyclones and showed that part of a misocyclone is characterised by strong descent, which would account for the holes in the clouds identified in the present Figure 1. The cloud holes observed in the present case are more commonly seen as gaps between successive segments or cores of line convection, as indeed was the case after the present example of line convection crossed southern England later that day. Core-gap rainband morphology has also been observed on oceanic NCFRs (Jorgensen et al, 2003; Wakimoto and Bosart, 2000), although the exact mechanism at work has been the subject of some debate. This case appears to have been a particularly striking visual example of the phenomenon.

\section{Acknowledgements}

The author wishes to acknowledge discussions with Matt Clark (Met Office) and Emeritus Professor Keith Browning and is grateful to the latter for reviewing an earlier draft of the manuscript. Original data for Figure 1 courtesy and copyright EUMETSAT.

\section{References}

Wakimoto, R. M., and B. L. Bosart, 2000: Airborne radar observations of a cold front during FASTEX.Mon. Wea. Rev.,128, 2447-2470.

Kidd C 2015.Letter to the editor. The narrow cold-frontal rainband of 22/23 November 2013. Weather 70: 246.

Jorgensen DP, Pu Z, Persson P, Tao W-K. 2003. Variations associated with cores and gaps of a Pacific narrow cold frontal rainband. Mon. Weather Rev. 131: 2705-2729.

Smart DJ and Browning KA. 2009. Morphology and evolution of cold-frontal misocyclones. 
Q.J.R. Meteorol. Soc., 135: 381-393.

Young MV. 2014. An unusual case of line convection - the birth of a classical cold front over the UK. Weather 69: 259-26.

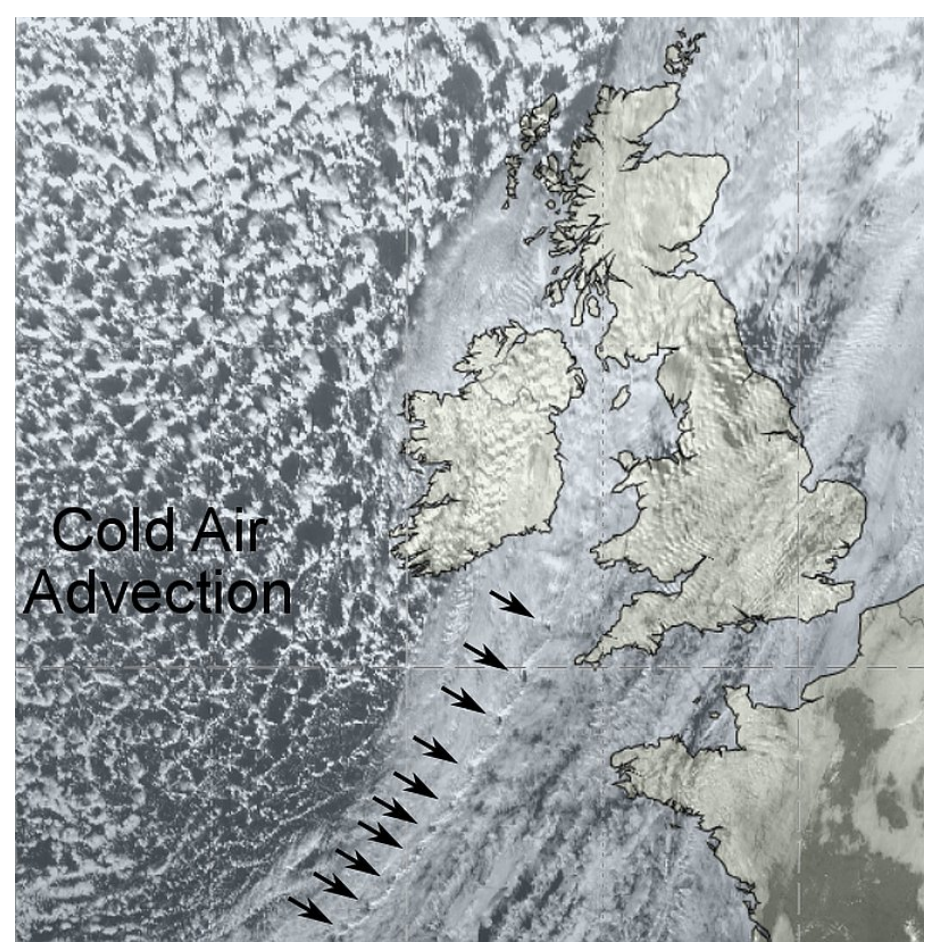

Figure 1. MSG visible satellite image of the North-East Atlantic at 1315 UTC 27 November 2015. See text for explanation of the annotations. (Original image courtesy \& copyright EUMETSAT.) 